\title{
Apium graveolens Prevents Intrauterine Growth Restriction via Suppression of Antiangiogenic Factor Production
}

\author{
Exma Mu'tatal Hikmah ${ }^{1}$, Paulus Liben ${ }^{2}$, Widjiati ${ }^{3}$ \\ ${ }^{1}$ Master Student in Basic Medical Science of Physiology, Faculty of Medicine, \\ Airlangga University, Indonesia \\ 2 Physiology Department, Faculty of Medicine, Airlangga University, Indonesia \\ ${ }^{3}$ Embryology Department, Faculty of Veterinary Medicine, Airlangga University, Indonesia
}

\begin{abstract}
Preeclampsia is the worldwide leading cause of fetomaternal morbidity and mortality which involves the placental dysfunction. A poor placentation and formed of non-dilated spiral artery caused uteroplacental circulation insufficiency, resulted in inadequate supply of nutrients and oxygen to support normal aerobic growth of the fetus. Apium graveolens or celery has been widely known as antioxidant, antiinflammation and antihypertensive with flavonoid-apigenin as main active compound. Apigenin can inhibit TNF- $\alpha$, HIF-1 $\alpha$ and nitric oxide blocking as major pathophysiological pathway of preeclampsia. This study was aimed to find how the Apium graveolens can improve intrauterine growth and its correlation with suppression of anti-angiogenic factor sFlt-1 in anti-Qa2 preeclampsia animal model. Twenty female BALB/c Mus musculus were divided into 4 groups: control, anti-Qa2 and anti-Qa2 with 500 and $1000 \mathrm{mg} / \mathrm{kgBW}$ celery herbs extract. The fetal weights and lengths, placental weights and serum sFlt-1 levels were measured and analyzed with One Way ANOVA and further tested with Least Significance Difference in 95\% confidence interval. The result showed a difference between control and treatments group ( $p \leq 0.05)$ with $1000 \mathrm{mg} / \mathrm{kgBW}$ significantly increase intrauterine growth and decrease sFlt-1, then there is a negative correlation between intrauterine weight and serum sFlt-1. This study suggests that celery herbs extract (CHE) has an apigeninflavonoid compound which can prevent intrauterine growth restriction (IUGR) via suppression of antiangiogenic factor production in preeclampsia mice model.
\end{abstract}

Keywords: Apium graveolens, preeclampsia, IUGR, sFlt-1

\section{INTRODUCTION}

Preeclampsia is present in $2 \%-8 \%$ pregnancies and one of the world leading cause of perinatal mortality and morbidity. In developing countries, almost ten percent maternal deaths incident is related to pregnancy hypertension with preeclampsia-eclampsia as the most major cause. Preeclampsia is referred to the disease of theories because the pathophysiology is not fully understood as many hypotheses have developed; placental vascularity abnormalities, placental ischemia, free radicals, endothelial dysfunction, immunological intolerance between mother and fetus, abnormal genetic cardiovascular adaptation, nutritional deficiency, and inflammatory theories (Ahmed, 2015; Powe, 2011; Steegers, 2010). Based on the high incidence mentioned above, World Health Organization in 2011 stated that optimizing health care to prevent and treat preeclampsia is still a necessary step toward development goals. Although the hypertension and proteinuria as the clinical manifestations have occurred in late second or third trimester of

Corresponding author : Exma Mu'tatal Hikmah Email : exma.mutatal.hikmah-2016@fk.unair.ac.id pregnancy, the pathogenesis began in early pregnancy as formed of non-dilated spiral artery (Powe, 2011).

Normal pregnancy requires immunematernal adaptation in $\mathrm{NK}$ cell activity for the trophoblast invasion (Lockwood, 2008). Imbalance between $\mathrm{T}$ helper $\mathrm{CD}^{+}$cell differentiation into Treg cells that induce immunologic tolerance and Th17 cells that cause inflammation or rejection reactions caused increasing inflammation cytokines; TNF- $\alpha$ and IL6 . This immune-maladaptation caused inadequate tolerance, chronic inflammation and poor angiogenesis then disturbed trophoblast invasian and reduced placental blood flow which supply nutrients and oxygen to fetus (Saito, 2010; Santner-Nanan, 2009). Furthermore, placental development requires vasculogenesis and angiogenesis, then a progression imbalance of the vascular endothelial growth factor (VEGF), placenta growth factor (PIGF) and angiopoietin during placental development resulted in adaptive angiogenesis in IUGR placental villi. VEGF also has VEGF receptors VEGFR-1 and VEGFR-2, which soluble form of VEGFR-1 (soluble Fms-tyrosine like/sFlt-1) has a strong antagonistic activity and 
neutralizes the effects mediated by VEGF and PIGF (Ahmed, 2000). The increase in sFlt-1 in preeclampsia is also caused by a response to hypoxia that also involves genetic and immunological factors. The increasing expression of sFlt-1 increases in response to hypoxia is mediated by hypoxia inducible factors $1-\alpha$ (HIF-1 $\alpha$ ) and Angiotensin II type1-receptor autiantibodies (AT1-AA) (Herse, 2013; Maynard, 2011).

Apium graveolens or Celery is a common plant which has active compounds with flavonoids apigenin and apiin as main contents. Apigenin in Celery has ability as an antioxidant, antiinflammatory (Kooti, 2017; Yao, 2010), antihypertensive (Jin, 2009; Zhang, 2002), antiischemic and antiarrhythmia (Occhiuto et al, 1991). Apigenin extracted from celery herbs has been shown as endothelial nitric oxide synthase (eNOS) stimulator and able to inhibit HIF-1 $\alpha$ expression as a factor causing placental hypoxia by blocking its interactions with HIF-1 $\alpha$-Hsp90 receptors (Manolescu, 2009; Olszanecki, 2002). Yamagata (2011) also stated that the flavon structure and double bonding on $\mathrm{C}$ ring in apigenin content of herb celery extracts can cause binding of ROS through inhibition of Tumor Necrosis Factor (TNF) $-\alpha$ and lectinlike oxidized LDL receptor- 1 (LOX -1).

In recent few years, many studies reported the prevention and treatment with the compound which able to bind inhibit sFlt-1 production and restore the vasculogenesis and angiogenesis function, such as VEGF121 recombinant, xanthone in mangosteen peel and thymoquinone in black cumin extracts (Rahma, 2017; Sulistyowati, 2017; Hidayati, 2015). The objective of the present study was to investigate whether the actions of Apium graveolens compound can prevent intrauterine growth restriction with reducing sFlt-1 production in preeclampsia animal model.

\section{METHODOLOGY}

\section{Experimental Design and Sampling}

This study was an experimental study using completely randomized design with twenty healthy female BALB/c mice (Mus musculus) which bred and cared in the Faculty of Veterinary Medicine, Airlangga University. All samples were randomly divided into 4 groups: control group, anti-Qa2 group, anti-Qa2+CHE $500 \mathrm{mg} / \mathrm{kgBW}$ and anti-Qa2+1000 mg/kgBW. The mice were housed in plastic cages with wooden chip bed in a temperature-controlled room $\left(23^{\circ} \mathrm{C}\right)$, given food and water ad libitum, and exposed to a light-dark cycle of 12:12 hours as its cyrcadian rhythm. All protocols were approved by the Animal Care and Use Committee (ACUC), Faculty of Veterinary
Medicine, Airlangga University No. 2.KE.001.01.2018.

\section{Mating Procedure}

All samples were injected with 5 IU Pregnant Mare's Serum Gonadotropin (PMSG PG 600, MSD Animal Health, Intervet Inc.), followed by human Chorionic Gonadotropin (hCG Chorulon, MSD Animal Health, Intervet Inc.) fourty-eight hours later. This method was done for oestrus cycle synchronization and prepared for mating following the procedures by The Practice Committee of the American Society for Reproductive Medicine in 2008. After the injection of hCG, all samples were mated one-on-one with mature male mice (aged 7 months and weighed \pm $40 \mathrm{~g}$ ). The presence of sperm plug seventeen hours later considered as day 0 of gestations.

\section{Anti-Qa2 Injection}

The treatment group was injected with anti-Qa2 10 ng i.p. on 1-4 days of gestations which has known that the implantation occurred approximately in a first quarter of murine pregnancy (Sones, 2016). Injection of anti Qa2 use the previous protocols by Sulistyowati (2010) that Qa2 was expressed in fifth day of gestations in normal mice, then the absence with anti-Qa2 injection i.v. has led to increasing of Heat Shock Protein (HSP-70) and Vascular Cell Adhesion Molecule-1 (VCAM-1) in preeclampsia. The previous study used the intravenous injection then we modify to intraperitoneal injection as it has similar efficient bioavailibility as i.v. which is impractical and at risk of mice perivascular trauma. Turner, et al (2011) in Journal of the American Association for Laboratory Animal Science also stated that intravenous injection routinely and has potential for severe complications, including blindness, cerebrovascular stroke, permanent motor deficits, and limb gangrene. Most previous preeclampsia animal model studies also used the intraperitoneal injection, such as TNF- $\alpha$ injection and human preeclampsia serum injection (Wicaksono, 2015; Kalkunte, 2010).

\section{Celery Herbs Extraction and Treatment}

Sterilized and shade air-dried Apium graveolens herbs were extracted with $70 \%$ ethanol maceration methods in the Phytochemical Laboratory of Materia Medica, Batu, Indonesia. Powdered celery herbs were soaked and shaked in ethanol $70 \%$, then filtered with filtration cloth. Filtrate were extracted for second and third time with additional solvent. The combined filtrate then evaporated and suspended in Na CMC 0.5\% 
suspending agent to a final concentration before use. The extracted celery herbs injected in treatment group in $6-15^{\text {th }}$ days of gestations as known in mid-first trimester until third trimester.

\section{Measurement of Results \\ Samples Termination}

All samples were terminated on the $16^{\text {th }}$ day of gestations as the third trimester of pregnancy which reflects the time preeclampsia onset (Sulistyowati, 2017). The surgical procedure was performed under general anesthesia using intramuscular injection of ketamine. Then, the number of fetus, any fetus with resorption and placental weight were measured. Each newborn fetus was weighed using analytical instruments and the lengths were also measured and documented.

Serum sFlt-1

Mice blood was directly taken from the right heart then centrifuged at $6000 \mathrm{rpm}$ for 10 minutes. Serum was taken and measured the sFlt1levels using ELISA kit (Bioassay Technology Laboratory, China, catalog number E0611Mo) and ELISA reader $450 \mathrm{~nm}$ wavelength.

\section{Statistical Analysis}

Collected data were tested with ShapiroWilk normality test and Lavene homogenity test. If the data were normal and homogeneous $(\mathrm{P} \geq 0.05)$, these were continued with 5\% One Way ANOVA analysis and further tested with LSD (Least Significance Difference) 5\% if there are significant differences $(\mathrm{P} \leq 0.05)$. Both intrauterine growth and serum sFlt-1 also tested with Pearson correlation test.

\section{RESULT AND DISCUSSION}

\section{A graveolens in Fetal and Placental Growth}

Anti Qa-2 group injection had lower the number of fetus born compared to normal group. Anti Qa-2 also increased the number of fetal resorption and reduced other characteristics as fetal weight, fetal length and placental weight. Anti Qa-2 caused growth restriction as normal fetuses $(0.233 \pm 0.18 \mathrm{~g})$ which bigger than anti Qa2 injection group $(0.792 \pm 0.32 \mathrm{~g})$ (see Table 1.), then celery herbs extract injection in both 500 $\mathrm{mg} / \mathrm{kgBW}$ and $1000 \mathrm{mg} / \mathrm{kgBW}$ show increasing of number of fetus, fetal weight $(0.432 \pm 0.19 \mathrm{~g}$ and $0.472 \pm 0.07 \mathrm{~g})$, fetus length and placental weight $(0.114 \pm 0.30$ and $0.129 \pm 0.11)$, followed by reducing the number of number of fetus with resorption with $P=0.00$ as significant difference in all of groups. In this study, we assumed that fetal growth restriction was symmetrically indicated by shorter fetal length in anti Qa-2 group which was $11.129 \mathrm{~mm}$ compared to normal group which was $23.038 \mathrm{~mm}(P$-value $=0.000 \leq 0.05)$, then celery herbs extract increasing fetus length as 13.830 $\mathrm{mm}$ in $500 \mathrm{mg} / \mathrm{kgBB}$ CHE and $15.818 \mathrm{~mm}$ in 1000 $\mathrm{mg} / \mathrm{kgBB}$ CHE.

The growth restriction due to anti Qa-2 injection as compared to preeclampsia might be caused by hypoxia while ischemia was caused by reduced placental blood flow. Previous studies using the same haplotype of mice showed that Qa2 is a murine homolog of Human Leukocyte Antigen-G (HLA-G) as non-classical Class Ib Major Histocompatibility Complex (MHC) located in Q region (Q6, Q7,Q8, and Q9) (Da Silva, 2017). HLA$\mathrm{G}$ regulation has been widely reported as the preimplantation embryonic development gene which plays an important role as Killer Inhibitory Receptor (KIR) ligand for maternal NK cell. The dysregulation of human leukocyte antigen (HLA)$\mathrm{G}$ was found in both placentas and maternal sera from preeclampsia patients (Tang, 2015; Djurisic, 2014; Durmanova, 2013). The disruption of placental development led to limited cytotrophoblast invasion of the arteries in the superficial decidua and the myometrial segments remained narrow and undilated (Maynard, 2011). The intrauterine growth restriction (IUGR) defined as is defined as a rate of fetal growth that is less than normal for the growth potential of a specific infant as per the race and gender of the fetus. The IUGR in preeclampsia is caused by maternal factor as preeclampsia is the disease with the effect on blood circulation, resulted in decrease in uteroplacental blood flow and lead to IUGR (Sharma, 2016). The placental factor in preeclampsia IUGR involved the decrease of terminal villi number and surface area which shows a malfunction of vascularization in pregnancy. As mentioned before, the adequate trophoblast invasion and an increase in uteroplacental blood flow is required with increase in gestation to meet the demand of growing fetus (Zygmunt, 2003). The intrauterine growth restriction caused by anti Qa-2 injection was also significantly shown (Pvalue $=0.000 \leq 0.05)$ which reduced placental weight $(0.085 \pm 0.05 \mathrm{~g})$ compared to normal group $(0.150 \pm 0.03 \mathrm{~g})$.

According to Cunningham (2014), placental dysfunction in preeclampsia is indicated by the miointima cells proliferation and tunica media necrosis. This mechanism started with lipids that accumulate in miointima cells and subsequently in macrophages and caused atherosis and uteroplacental blood flow disruption. 


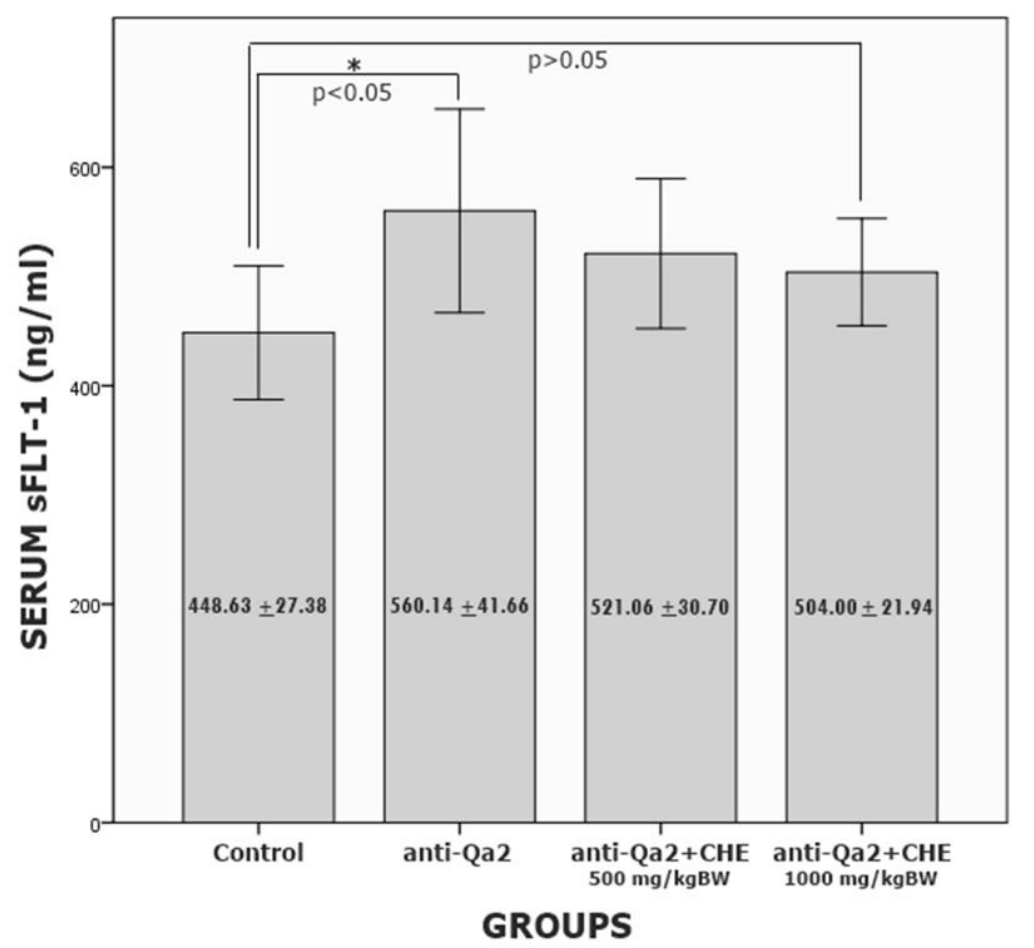

Figure 1. Injection of anti Qa-2 resulted in increased of sFlt-1 compared to control group (*showed significantly different, $\mathrm{p} \leq 0.05$ ), then $1000 \mathrm{mg} / \mathrm{kgBW}$ celery herbs extract reducing serum sFlt-1 which did not show significantly different with control group $(\mathrm{p} \geq 0.05)$.

Furthermore, celery has been commonly known to have antihypertensive effects through antioxidant-relaxation dependent pathway, increased nitric oxide (NO) and antiproliferation of vascular smooth muscle (Jorge, 2013; Jin, 2009; Zhang, 2002). This effect was shown to increase placental blood flow, as indicated by the increased placental weight of the anti-Qa2 group $0.085 \pm$ $0.05 \mathrm{~g}$ to $0.114 \pm 0.30 \mathrm{~g}$ and $0.129 \pm 0.11 \mathrm{~g}$ in the celery group 500 and $1000 \mathrm{mg} / \mathrm{kgBW}$, followed by the increased of fetal weight.

\section{Apium graveolens in sFlt-1 Serum Levels}

Figure 1 shows that anti-Qa2 group having higher serum sFlt-1 levels than control ( $p \leq 0.05$ ), then the anti-Qa2 group with the treatment of 500 celery herbal extracts and $1000 \mathrm{mg} / \mathrm{kgBW}$ show decreased sFlt-1 levels. In addition, at the sFlt-1 level in the group with the CHS treatment 1000 $\mathrm{mg} / \mathrm{kg}$ BW did not differ statistically with the control group $(p \geq 0.05)$. Celery has been known to inhibit the increase of TNF- $\alpha$ and HIF- $1 \alpha$ which are the activation paths of AT1-AA which causes an increase in sFlt-1. This sFlt-1 supression by celery restores the VEGF angiogenesis function, decreases the clotting factor and restores the endothelial function to improve the blood flow to the placenta (Yamagata, 2011; Manolescu, 2009). This effect has been proved with Pearson correlation test among sFlt-1 levels, fetal weights, fetal lengths, placental weights which shows that sFlt-1 has strong negative correlation with each intrauterine growth characteristic $(\mathrm{P} \leq 0.05)$. These results indicated that the decrease of sFlt- 1 by celery caused an increase in the growth of fetus and placenta.

Table II shows that sFlt- 1 has negative correlation to fetal weight, fetal length and placental weight with high coefficient of Pearson correlation $-0.648,-0.610$, and -0.621 respectively. Herraiz (2015) has reviewed the role of sFlt-1 as angiogenesis-related biomarkers in placental dysfunction which resulted in inhibit intrauterine growth. sFlt-1 mRNA as alternative splicing of the Flt-1 gene has generated in response to hypoxia, then sFlt- 1 is produced and secreted from the placenta to the maternal circulation, causing a reduction of the inhibition of proangiogenic factors. This mechanism will disrupt the remodeling of the spiral arteries in their myometrial segments during normal pregnancy and regulation of the flow pressure to the intervillous space. This led to the appearance of hypoperfusion-reperfusion phenomena, 
Table I. The fetal growth in each group, shows the number of fetus born and fetus with resorption. Fetal weights, lengths and placental weights were statistically different ${ }^{*} \mathrm{p} \leq 0.05$

\begin{tabular}{lccccc}
\hline Comparison of Variable & $\begin{array}{c}\text { Number } \\
\text { of pups }\end{array}$ & $\begin{array}{c}\text { Number of pups } \\
\text { with resorption }\end{array}$ & $\begin{array}{c}\text { Pup } \\
\text { Weights (g) }\end{array}$ & $\begin{array}{c}\text { Pup lengths } \\
\text { (mm) }\end{array}$ & $\begin{array}{c}\text { Placental } \\
\text { weights (g) }\end{array}$ \\
\hline Control (n=5) & $\mathbf{8 6}$ & 1 & $0.792 \pm 0.292$ & $23.038 \pm 6.063$ & $0.150 \pm 0.034$ \\
anti Qa2 mice (n=5) & 78 & 14 & $0.233 \pm 0.179$ & $11.129 \pm 4.272$ & $0.085 \pm 0.039$ \\
CHE 500 mg/kgBW (n=5) & 75 & 10 & $0.432 \pm 0.188$ & $13.830 \pm 4.022$ & $15.818 \pm 2.038$ \\
CHE 1000 mg/kgBW (n=5) & 87 & 11 & $0.472 \pm 0.075$ & $0.114 \pm 0.029$ & $0.129 \pm 0.109$ \\
P-value & - & - & $0.000^{*}$ & $0.000^{*}$ & $0.000^{*}$ \\
\hline
\end{tabular}

Table II. Matrix of bivariate correlations among sFlt-1 levels, Fetal Weights, Fetal Lengths, Placental Weights

\begin{tabular}{llcccc}
\hline Variable & sFlt-1 & $\begin{array}{c}\text { Fetal } \\
\text { Weights }\end{array}$ & $\begin{array}{c}\text { Fetal } \\
\text { levels }\end{array}$ & $\begin{array}{c}\text { Placental } \\
\text { Weights }\end{array}$ \\
\hline sFlt-1 levels & Pearson correlation & 1 & $-0.648^{* *}$ & $-0.610^{* *}$ & $-0.621^{* *}$ \\
& $P$-value & & 0.002 & 0.004 & 0.004 \\
Fetal Weights & Pearson correlation & & 1 & $0.907^{* *}$ & $0.776^{* *}$ \\
& $P$-value & & 0.000 & 0.000 \\
Fetal Lengths & Pearson correlation & & & & $0.823^{* *}$ \\
& $P$-value & & & 0.000 \\
Placental Weights & Pearson correlation & & & & 1 \\
& $P$-value & & & \\
\hline
\end{tabular}

${ }^{* *}$ correlation is significant at the 0.01 level (2-tailed)

then caused villous damage and an impairment of the maternal-fetal exchange, resulted in intrauterine growth restriction. Previous studies used the herbal product to preeclampsia treatment has done by Rahma (2017) which explained how the thymmoquinone in Nigella sativa decreased placental angiotensin II type 1receptor autoantibody (AT1-AA) serum levels and endothelin-1 (ET-1) expression. Hidayati (2015) also studied that mangosteen peel extract decreased Nf-кB, sFlt-1, TNF- $\alpha$, blood pressure and proteinurine in preeclampsia. The herbal product with antioxidant and angiogenic ability could decrease sFlt-1, AT1-AA and increase VEGF and resulted in prevention of IUGR as explained in the studies by Sulistyowati (2017) and Soetrisno (2017) with recombinant VEGF and L-arginine injection.

\section{CONCLUSION}

This study suggests that herb celery extract in $1000 \mathrm{mg} / \mathrm{kgBB}$ can prevent intrauterine growth restriction via suppression of antiangiogenic factor production in preeclampsia mice model. The possible pathway is a celery apigenin-flavonoid compound which inhibit TNF$\alpha$ and HIF- $1 \alpha$ actions.

\section{REFERENCES}

Ahmed, A. \& Perkins, J., 2000, 'Angiogenesis and intrauterine growth restriction', Best Pract. Res. Clin. Obstet. Gynaecol. 14, 981-998

Ahmed, A. \& Ramma, W., 2015, 'Unravelling the theories of pre-eclampsia: Are the protective pathways the new paradigm?', Br. J. Pharmacol. 172, 1574-1586

Cunningham, F. G., Leveno, K. J., Bloom, S. L., Spong, C. Y., Dashe, J. S., Hoffman, B. L., Sheffield, J. S., 2014, Williams obstetrics (24th edition). New York: McGraw-Hill Education

Da Silva, I. L. et al., 2017, 'Reduced expression of the murine HLA-G homolog Qa-2 is associated with malignancy, epithelialmesenchymal transition and stemness in breast cancer cells', Sci. Rep. 7, 1-11

Djurisic, S. \& Hviid, T. V. F., 2014, 'HLA class Ib molecules and immune cells in pregnancy and preeclampsia', Front. Immunol. 5, 1-17

Durmanova, V., Homolova, M., Drobny, J., Shawkatova, I. \& Buc, M., 2013, 'Role of HLA-G and other immune mechanisms in pregnancy', Open Life Sci. 8

Herraiz, I. et al., 2015, 'Angiogenesis-related biomarkers (sFlt-1/PLGF) in the prediction 
and diagnosis of placental dysfunction: An approach for clinical integration' Int. J. Mol. Sci. 16, 19009-19026

Herse, F. \& LaMarca, B., 2013, 'Angiotensin II type 1-Receptor Autoantibody (AT1-AA)mediated pregnancy hypertension', $\mathrm{Am} J$ Reprod Immunol 76, 211-220

Hidayati, R. \& Kalim, H., 2015, 'Mangosteen Peel Extracts Decreased NfK-B, sFlt-1, TNF- $\alpha$, Blood Pressure and Proteinurine in Mouse Model of Preeclampsia', J. Appl. Environ. Biol. Sci. 5, 1-8

Jin, B. et al, 2009, 'Apigenin protects endotheliumdependent relaxation of rat aorta against oxidative stress'. Eur. J. Pharmacol. 616, 200-205

Jorge, V. G., 2013, 'Vasorelaxant activity of extracts obtained Possible source for vasorelaxant molecules antihypertensive effect from Apium graveolens : isolation with potential antihypertensive effect' Asian Pac. J. Trop. Biomed. 3, 776-779

Kalkunte, S. et al., 2010, 'Sera from preeclampsia patients elicit symptoms of human disease in mice and provide a basis for an in vitro predictive assay', Am. J. Pathol. 177, 23872398

Kooti, W. \& Daraei, N., 2017, 'A Review of the Antioxidant Activity of Celery (Apium graveolens L.)', J. Evid. Based. Complementary Altern. Med. 1-6

Lockwood, C. J. et al., 2008, 'Preeclampsia-Related Inflammatory Cytokines Regulate Interleukin-6 Expression in Human Decidual Cells', Am. J. Pathol. 172, 15711579

Manolescu, B., Oprea, E., Busu, C. \& Cercasov, C., 2009, 'Natural compounds and the hypoxiainducible factor (HIF) signalling pathway', Biochimie 91, 1347-1358

Maynard, S. E. \& Karumanchi, S. A., 2011, 'Angiogenic Factors and Preeclampsia', Semin. Nephrol. 31, 33-46

Olszanecki, R., Gebska, A., Kozlovski, V. I. \& Gryglewski, R. J., 2002, 'Flavonoids and nitric oxide synthase', J. Physiol. Pharmacol. $53,571-584$

Powe, C. E., Levine, R. J. \& Karumanchi, S. A., 2011, 'Preeclampsia, a disease of the maternal endothelium: The role of antiangiogenic factors and implications for later cardiovascular disease', Circulation 123, 2856-2869

Rahma, H., Indrawan, I. W. A., Nooryanto, M., Rahajeng \& Keman, K., 2017, 'Effect of a black cumin (Nigella sativa) ethanol extract on placental angiotensin II type 1-receptor autoantibody (AT1-AA) serum levels and endothelin-1 (ET-1) expression in a preeclampsia mouse model'. J. Taibah Univ. Med. Sci. 1

Saito, S., 2010, 'Th17 cells and regulatory T cells: new light on pathophysiology of preeclampsia'. Immunol. Cell Biol. 88, 615617

Santner-Nanan, B. et al., 2009, 'Systemic Increase in the Ratio between Foxp3+ and IL-17Producing CD4+ $\mathrm{T}$ Cells in Healthy Pregnancy but Not in Preeclampsia', J. Immunol. 183, 7023-7030

Sharma, D., Shastri, S., Farahbakhsh, N. \& Sharma, P., 2016, 'Intrauterine growth restriction part 1', J Matern Fetal Neonatal Med. 29(24): 3977-3987

Soetrisno, Sulistyowati, S., \& Wibowo, A.S., 2017, 'L-arginine improves uterine spiral arterial wall thickness in mouse models of preeclampsia', Univ Med, 36:131-7

Sones, J. L. \& Davisson, R. L., 2016, 'Preeclampsia, of mice and women', Physiol. Genomics 48, 565-572

Steegers, E. A. P., Von Dadelszen, P., Duvekot, J. J. \& Pijnenborg, R., 2010, 'Pre-eclampsia', Lancet 376, 631-644

Sulistyowati, S., Abadi, A. \& Wijiati, 2010, 'Low Class Ib (HLA-G/Qa-2) MHC Protein Expression against Hsp-70 and VCAM-1 Profile on Preeclampsia. An observation on experimental animal Mus Musculus with Endothelial Dysfunction model', Indones J Obs. Gynecol 34, 103-107

Sulistyowati, S. et al., 2017, 'Recombinant vascular endothelial growth factor 121 injection for the prevention of fetal growth restriction in a preeclampsia mouse model', J. Perinat. Med. 45, 245-251

Tang, Y. et al., 2015, 'Hypermethylation of the HLA-G promoter is associated with preeclampsia' Mol. Hum. Reprod. 21, 736744

The Practice Committee of the American Society for Reproductive Medicine, 2008, 'Gonadotropin preparations: past, present, and future perspectives', Fertil. Steril. 90, $13-20$

Turner, P. V, Brabb, T., Pekow, C. \& Vasbinder, M., 2011, 'Administration of substances to laboratory animals: routes of administration and factors to consider', $J$ Am Assoc Lab Anim Sci 50, 600-613

Wicaksono, B. A., Candra, S., Baktiyani, W. \& Fitri, L. E., 2015, 'Intraperitoneal Injection of High Tumor Necrosis Factor (TNF- $\alpha$ ) Serum Increase Soluble Fms-like Tyrosine 
Kinase 1 (sFlt-1) and Blood Pressure of Pregnant Mice', J. Trop. Life. Sci. 5, 8-13

Yamagata, K., Miyashita, A., Chino, M. \& Matsufuji, H., 2011, 'Apigenin inhibits tumor necrosis factor alpha plus high glucose-induced LOX-1 expression in human endothelial cells', Microvasc. Res. 81, 60-67

Yao, Y., Sang, W., Zhou, M. \& Ren, G., 2011, 'Phenolic composition and antioxidant activities of 11 celery cultivars', J. Food Sci.
75, 9-13

Zhang, Y., Park, Y., Kim, T., Fang, L. \& Ahn, H., 2002, 'Endothelium-dependent vasorelaxant and antiproliferative effects of apigenin', Gen. Pharmacol. 35, 341-347

Zygmunt, M., Herr, F., Münstedt, K., Lang, U., Liang, O.D., 2003, 'Angiogenesis and vasculogenesis in pregnancy', Eur J Obstet Gynecol Reprod Biol. 22;110 Suppl 1:S10-8. 